\title{
Blockchain Use Cases Revisited: Micro-Lending Solutions for Retail Banking and Financial Inclusion
}

\author{
Christian Hugo HOFFMANN \\ University of Zurich, Deputy Director of the Swiss FinTech Innovation Lab, Head of Artificial \\ Intelligence (AI), Plattenstrasse 14, 8032 Zurich, Switzerland \\ E-mail: christian.hoffmann@bf.uzh.ch
}

\begin{abstract}
While blockchain technology is commonly considered potentially disruptive in various regards, there is a lack of understanding where and how blockchain technology is effectively applicable and where it has remarkable practical effects ${ }^{[1]}$. Against this background, we present and discuss a case study at length on the impact of this technology in the concrete setting of small short-term loans in retail banking. We propose to banks a robust and scalable blockchain technology with proof of stake and limited energy consumption used to streamline their processes, resulting in lower transaction and administration costs. This is made possible by smart contracts. Thereby, we facilitate small scale lending at high frequencies and short-term duration as well as an easier and more efficient way to connect small borrowers and lenders.
\end{abstract}

Keywords design science; blockchain; smart contracts; asymmetric information; fintech; microfinance

\section{Introduction}

In 2008, the Satoshi Nakamoto alias introduced the Bitcoin digital currency to the world with the intent of enabling electronic cash payments directly between individuals without the need for third-party intermediaries. Since then, blockchain, the technology behind Bitcoin, has captured a substantial amount of interest from researchers and practitioners. While research on some forms has rapidly developed, particularly in connection with cryptocurrencies, many experts have realized that blockchain technology holds disruptive potential beyond its use in cryptocurrencies $^{[2-4]}$. Yet, a profound understanding regarding terms of application and usecases is generally missing ${ }^{[1]}$. In other words, to dismiss the concern that blockchain is an innovative technology in search of use cases ${ }^{[5]}$ or that few blockchain centric projects have gone beyond their white paper or proofs-of-concept ${ }^{[6]}$, more knowledge has to be gained regarding which (combinations of) features are relevant for particular industries or business processes and how they need to be designed. These types of questions need to be addressed in order to influentially deploy the technology to business cases ${ }^{[1]}$.

Following [1], we argue that research can help overcome this paucity by comprehensively understanding the relevance and effects of unique blockchain properties (e.g., decentralization, transaction speed, energy needs) and by investigating respectively appropriate use cases. The

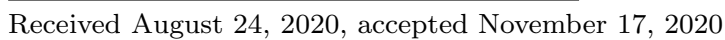


use case we sketch in the subsequent case study is about lending practices at high frequencies but very low in volume. It starts from the observation of a business problem in retail banking where retail banks' clients asking for small short-term loans to cover an unexpected expense are left without finding a good answer to their needs. Retail banks usually do not offer such loans. Friends, family (and fools) might feel uncomfortable or make the lender feel uncomfortable. Credit cards are too expensive and loan sharks or private loan businesses all too often follow predatory lending practices.

To address this problem, we design a blockchain- and smart contract-based solution for retail banks which can be made available in a cost-effective, safe and scalable manner, unlike the currently existing and oftentimes unlawful payday loans ${ }^{[7-9]}$.

The contribution of this study to existing research is threefold: First, it presents a concrete use and potential business case by introducing a built-in mechanism to reduce transaction and administrative costs resulting from an obsolete lending practice at banks. Second, it replaces a trust-based, centralized, and bureaucratic register with a tamper-free and autonomous transactional database system that comprises a secure registration and transaction process. Third, it makes use of a novel design science approach to draw a strategy of how to mitigate adverse selection effects in markets plagued by information asymmetries through the provision of a reliable, transparent, and complete record of each marketable asset's history. In total, the findings in this article illustrate the potential of blockchain/smart-contract-based systems for a core business activity in banking, but also highlights technological shortcomings and challenges for commercial applications, such as scalability or privacy issues.

The remainder of this paper is structured as follows. Subsequently, in Section 2, we first elaborate on the problems that come with micro lending in retail banking, mainly high costs and information asymmetries. Section 3 clarifies that this work follows a design science research approach to guide the implementation of a blockchain-based prototype. Section 4 briefly analyses the blockchain landscape in financial services, thereby emphasizing on the energy problem as well as the proof of work vs. proof of stake mechanisms for mining. We propose and design a workable application for a blockchain-based microlending platform in Section 5. It is discussed thereafter at length, including a market description and a Business Model Canvas. Section 6 evaluates the proposal on the basis of a SWOT analysis. Section 7 concludes and derives lessons for research and practice.

\section{Problem Statement: Cost-Intensive Micro Lending and Informa- tion Asymmetry}

Microfinance has been a buzzword in the realm of economic development ever since Dr. Muhammad Yunus was awarded the Nobel Peace Prize 2006, in homage to his efforts in improving the life of the poorest of the poor by the provision of micro-loans. With the further expansion of microfinance institutions around the globe, the model started having multiple mutations that have brought a mix of positive and negative outcomes, raising questions about the feasibility and effectiveness of microfinance as an economic development tool ${ }^{[10,11]}$. In contrast to this known and established, but also controversial application of microfinance, we propose to embed it in general retail banking. Yet, in both forms, be it as a development aid tool 
or a product in classical retail banking, microfinance comes with some peculiarities that have hindered financial institutions from adopting it.

Transaction, loan, mortgage and payment services comprise the core of the banking repertoire but often rely on outdated, legacy processes of execution. Information verification, credit scoring, loan processing, and the distribution of funds are all services that take time ${ }^{[12]}$. Clients asking for small, short-term loans have historically been excluded due to the high fixed-costs associated with transaction fees and administrative costs. The cost of acquiring clients compared to the size of the loan is drastically higher in microfinance compared to regular commercial loans ${ }^{[13]}$. A survey performed by Lascelles and Mendelson (2008) spotted 20 risk factors that could deter the growth in the microfinance sector. Among these factors, cost control is ranked as the fourth most relevant. This indicates that efficiency in operations is vital for retail banks and microfinance institutes ${ }^{[14]}$. Hence, the absence of microlending in retail banking as well as the high interest rates for micro-loans in the developing world. Therefore, an efficient and safe way to manage these transactions could significantly aid both the lenders, with higher benefits by eliminating or transforming the nature of the middle men, and the loan holders, by having access to small, short-term loans with less interests to pay and mechanisms that can prevent over-leveraging ${ }^{[13]}$. In an economic perspective, decentralized ledgers are likely to be more cost-efficient compared to the current centralized systems as blockchain goes through three exponential cost curves: Moore's law (cost of processing digital information decreases exponentially), Kryder's Law (cost of storing digital information decreases exponentially), and Nielsen's Law (the cost of transferring digital information decreases exponentially) ${ }^{[15]}$.

An important cost driver in the setting of microfinance are information asymmetries, and thus their reduction would bear a positive impact in costs reduction ${ }^{[16]}$. Banks and microfinance institutes often do not have enough information to make an informed credit decision - The unbanked (estimated to be $40 \%$ of the global population), the underbanked, and the microenterprises often have not made enough non-cash payments for a sufficient risk assessment ${ }^{[17]}$.

Generally, information asymmetry means that one party lacks crucial information about another party, impacting decision-making. We usually discuss this problem along two fronts: Adverse selection and moral hazard. Adverse selection describes a situation in which interacting parties attach value to the quality of a transacted object but at the same time possess different levels of information about it ${ }^{[18]}$. Second, moral hazard refers to (some) beneficiaries' tendency to use their loans in projects that would deter their ability of repayment, or the propensity of microfinance institutes to require collateral and loan policies disadvantageous for the borrowers.

The varied ownership structure and diversity of stakeholders in microfinance render the information asymmetry the main source of risk for microfinance institutes ${ }^{[19]}$. Arguably, the economic and regulatory environments in developing countries are more likely to give rise to deeper asymmetries with negative pervasive effects ${ }^{[16]}$. In this regard of information asymmetries, the deployment of blockchain can bring relief too.

\section{Methodology and Design Research}

There is emerging recognition of design research in Information Systems as a natural evolution of our field as it matures ${ }^{[20]}$. Like others before ${ }^{[21]}$, this work follows design science research 
to guide the implementation of a block chain-based business concept. In terms of design science, microlending in retail banking is a typical "wicked problem" since 1) it may only be possible to find a solution to the problems of high costs and information asymmetries in micro-lending that is "good enough", rather than solving them completely; 2) the solution to the problem will be good-or-bad rather than true-or-false; 3) testing the solution is complicated and depends on several contributing actors; 4) the possibility to learn by trial-and-error is limited as every attempt at testing the solution is complicated and resource-intensive; and 5) the problem does not have an exhaustively describable set of potential solutions or a set of well-described permissible operations. We therefore chose the ad hoc development approach by first learning more about the twofold problem in the previous section and then designing a draft in Section 5 , which we concurrently and conclusively evaluated (Section 6). Therefore, our design process follows the DSRM Process Model introduced by [22], see Figure 1.

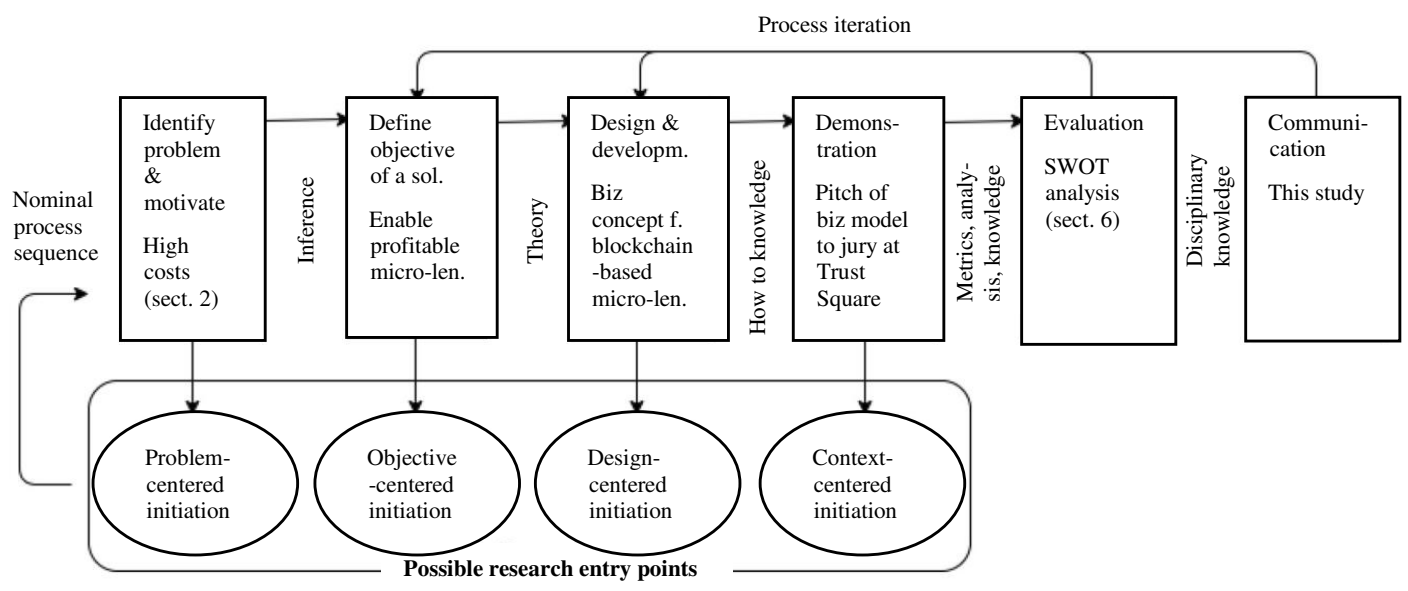

Figure 1 The design science research process

In our case, the research entry point was context initiated by my Master course on blockchain at the University of Zurich in the spring term of 2020. During the course of that class, we reviewed literature from various sources such as academic papers, industry leader reports, and other publications (see Section 8) to construct a landscape of current digitalization trends in the financial industry in general and specifically with regard to blockchain technology applications. We researched the most pressing technical issues that need to be addressed to make sure our solutions could be applied in practice. We interviewed blockchain experts at Trust Square in Zurich and banks directly to validate our approach. When formulating ideas, we focused on solutions that would leverage the existing financial institutions and structures, enhanced by blockchain technology, to provide more value to the clients on the lower-end of the income spectrum in the developed world in the short-term and underbanked in the developing world in the long-run. Next, different ideas were researched and tested in student groups who prepared a preliminary business plan for each one, finally narrowing down the number of solutions to just the one we pursue in this paper. We then conducted a market analysis and attempted to position our lending solution for maximum market penetration, the results of which are presented in the following. 


\section{Analysis of Blockchain Features}

\subsection{Blockchain and Financial Services}

Our discussion centers around blockchain technology in retail banking. It is independent though of cryptocurrencies and their value as a portfolio asset which is currently also a prominent topic in the financial services industry (see [23] for an overview).

The financial services were expected to lead blockchain spending in 2019 with $\$ 1.1$ billion of the expected 2.9 billion across all sectors ${ }^{[24]}$. Spending is expected to grow exponentially through 2022 , hitting $\$ 12.4$ billion across all sectors ${ }^{[24]}$. There are many ways in which blockchain can improve upon the current financial system, with the most important being security, transparency, trust, and cost reductions ${ }^{[25]}$. Firstly, blockchain offers the possibility of making the system more secure through its consensus-based architecture, which eliminates single points of failure and reduces the need for intermediaries. Secondly, it can decrease information asymmetries, increase transparency and reliability in the system, acting as a single, immutable shared data source for all participants. Thirdly, it has the potential to significantly reduce costs by allowing financial institutions to eliminate a large number of intermediaries. As a result, many people who were previously barred from participating in financial services due to the high barrier of entry fees, can now participate and reap the benefits.

In particular, with regard to our use case, blockchain technology can be employed to streamline loan processes by enabling, for example, real-time verification of documents, streamlined credit prediction and automated disbursement of funds through smart contracts ${ }^{[25]}$.

\subsection{Blockchain Technology and Smart Contracts}

In its generic form, blockchain technology refers to a fully distributed system for cryptographically capturing and storing a consistent, immutable, linear event log of transactions between networked actors ${ }^{[1]}$. It creates a decentralized record of transactions, known as the distributed ledger, that allows the current proprietary databases to be substituted by a single, immutable master database. Essentially, it means that any party can trust the data stored on a blockchain. As current blockchain technology can not only process monetary transactions but can also ensure that transactions comply with programmable rules in the form of "smart contracts" [26], it allows even parties who do not fully trust each other (like in our context of microlending) to conduct and reliably control mutual transactions without relying on the services of any trusted middlemen.

To achieve a "democratisation" of finance, we need the tools made possible by a blockchain, specifically smart contracts. A smart contract is a computer protocol which can verify and execute the provisions of a contract without the need for trusted third-party intermediaries. The terms of the agreement are written directly into the code and once the requirements are fulfilled, the contract is executed. All transactions performed by means of a smart contract are trackable and irreversible. They are the key ingredient for the performance speed and trustlessness of blockchain lending applications as we envision it.

All of these applications, however, require the blockchain technology behind them to be robust, energy efficient, and capable of processing thousands of transactions per day. In theory, blockchain solutions ought to rival and overtake the processing capabilities of credit cards. Visa, 
for example, processes around 1,700 transactions per second, but claims to have the capacity to process more than 65,000 per second as of March, 31st 2019 ${ }^{[27]}$. Blockchains currently fall short of that by a significant margin. In the next section, we look at the energy issue of blockchain technology that is responsible for this shortfall and how it can be addressed.

\subsection{The Energy Problem}

Blockchain technology still faces a plethora of issues that hinder its large-scale adoption in the financial services industry. Arguably, one of the larger hurdles right now is scalability due to the prohibitive amounts of energy needed to add new blocks of information to the blockchain (see Figure 2). At this point in time, blockchain technology is not available to most retail clients.

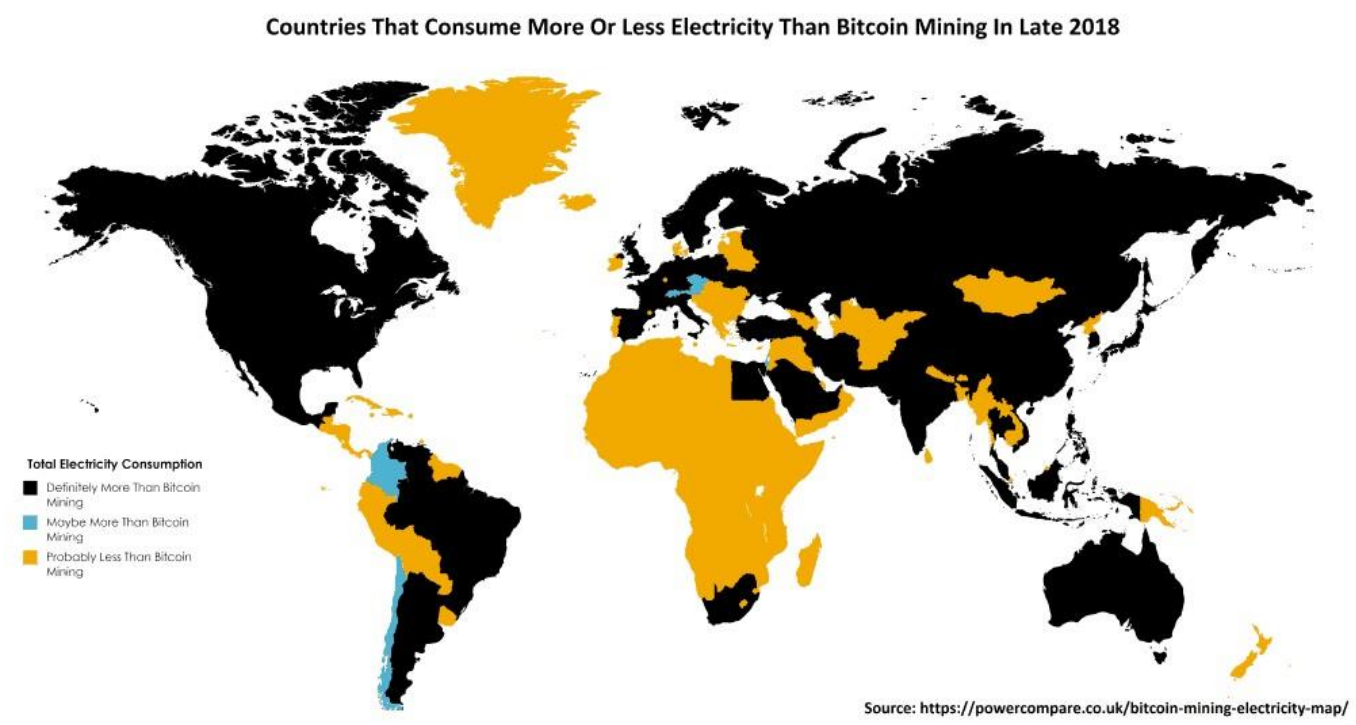

Figure 2 Country energy consumption vs. Bitcoin energy consumption

Blockchains require plenty of energy which may indeed be regarded as disproportionate when compared to the currencies' actual utility ${ }^{[28]}$ and which could thus therefore inhibit or delay the widespread adoption of blockchain technology ${ }^{[29]}$. Exactly how much is not a simple question to answer. Key data about blockchains is hard to come by. Their activities can, however, be proxied by the necessary coin needed to run them. The largest blockchain is the one running on bitcoin ${ }^{1}$ and bitcoin mining (the process of writing transactions on the blockchain) is energy expensive. Approximations place the energy consumption of Bitcoin at around $75 \mathrm{TWh}$ annually ${ }^{[30]}$. For comparison, that is more than what the country of Nigeria consumes as a whole and more than the lowest 750 million electricity users (10\%) worldwide. As can be seen in Figure 2, electricity consumption of Bitcoin has overtaken most of Africa and only 38 countries remain that definitely consume more in electricity ${ }^{[31]}$.

Figure 3 shows us that Bitcoin's electricity consumption was fairly steady over the past year. This is due to the fact that the electricity needed to run the bitcoin blockchain has become a

\footnotetext{
${ }^{1}$ We use the bitcoin blockchain as an example due to data availability.
} 
significant cost factor in the implementation of blockchain solutions in the financial industry, slowing down the spread of large-scale blockchain solutions.

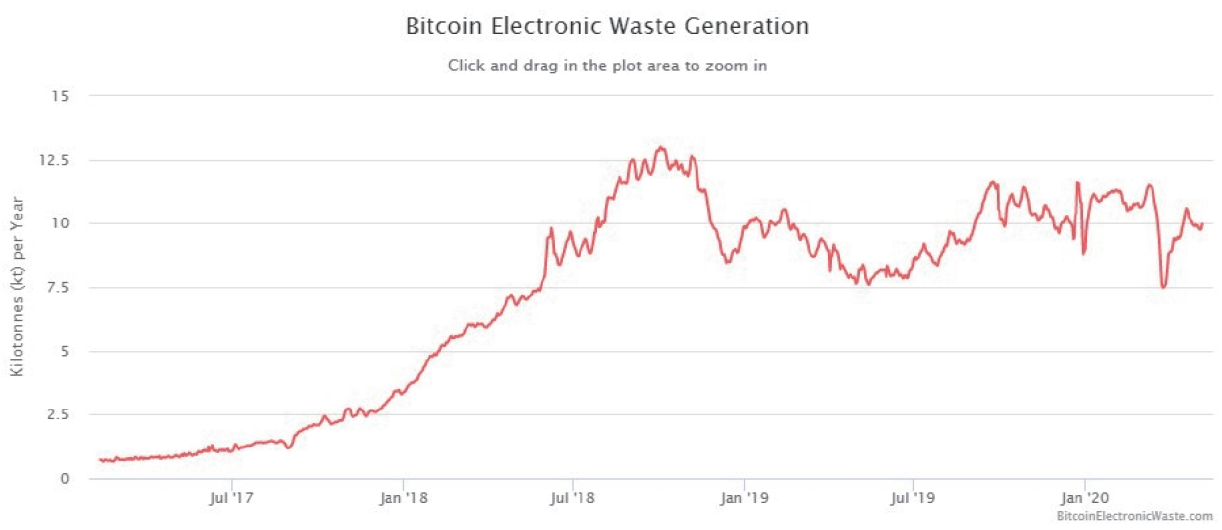

Figure 3 Energy consumption of the Bitcoin Blockchain

Source: https://digiconomist.net/bitcoin-electronic-waste-monitor/

There are three reasons for this enormous usage of power:

1) Artificial scarcity of the coins leading to a large number of miners;

2) Increasing competition for the remaining coins, again increasing the number of miners;

3) And most importantly, the proof of work (PoW) mechanism ${ }^{[28]}$.

Points 1 and 2 are supply and demand interactions that are unlikely to change. The proof of work mechanism in point 3 , however, is the real energy ${ }^{2}$ culprit ${ }^{[32,33]}$. Simply put, PoW is the game-theoretical mechanism by which blockchains guarantee the security and workability of the "chain". To work, it requires miners. Miners are machines competing to contribute to the blockchain by solving complex prime number factorisation puzzles. These puzzles require a brute force, energy intensive approach, but the real issue is in the duplication of work ${ }^{[28,33]}$. As the mining process is a winner takes all scenario, thousands compete for the same reward every minute of every day. More than $99 \%$ of the participants will not claim the prize but still compete and do the work because the expected rewards are worth the efforts. By this duplication, the energy consumed to confirm a simple transaction on blockchains can be hundred to ten-thousand times higher than needed. In short, widespread implementation of blockchain, for example in retail banking, is not sustainable ${ }^{[33,34]}$. It is due to this energy consumption issue that blockchains did not yet see widespread implementation and scalability in the retail financial services industry.

\subsection{Proof of Work vs. Proof of Stake}

We established the PoW mechanism and its energy consumption to be a massive obstacle to widespread adoption of PoW-based blockchain solutions. Many alternatives are currently being explored, most common of which is the proof of stake (PoS) mechanism ${ }^{[33]}$. The second largest blockchain in the world, Ethereum (in terms of market capitalization), has already announced plans to adopt this mechanism in the future.

\footnotetext{
${ }^{2}$ Energy is largely electricity but hardware manufacturing and expensive commodities needed, such as rare earths, are part of the issue as well.
} 
PoS requires an investment (a stake meaning an amount of currency) by the miner before they can participate to ensure they are still incentivized to uphold the security aspects that are key to the blockchain technology. In essence, a miner needs to pay to participate.

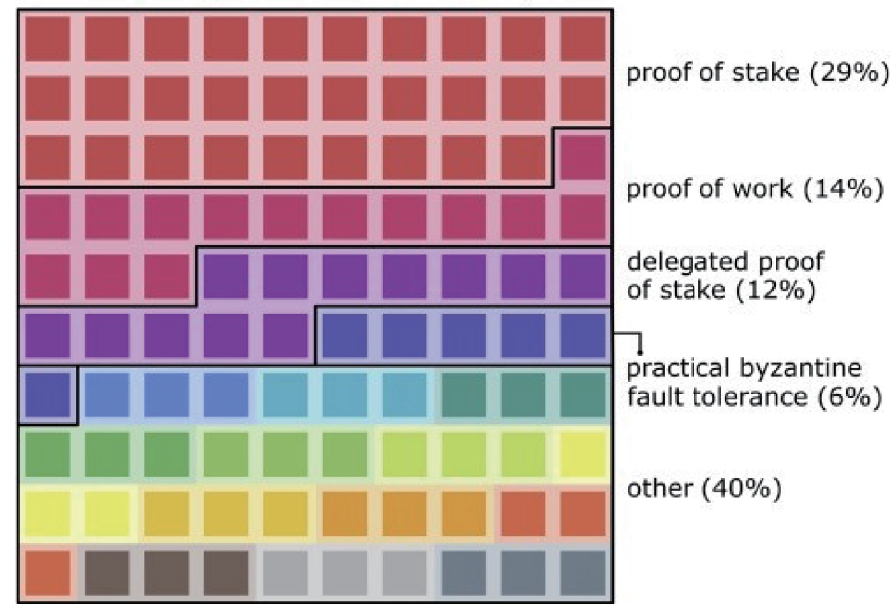

Figure 4 Consensus algorithm of blockchain platforms. Source: Sutherland, $2019^{3}$

PoW is essential to the security of the blockchain as it allows trustless and distributed consensus which means we no longer need a bank or a trusted intermediary. Instead, PoW relies on a game-theoretical, self-enforcing mechanism to make sure everything is done accurately. PoS replicates the process but instead of it being a free-for-all competition, one miner is awarded the job. The idea is to reduce the number of miners from many hundreds or even thousands down to a single actor per transaction, thereby slashing energy consumption by $99 \%$ or more.

Having discussed the current trends of blockchain in finance and some of the issues that still lie ahead, we narrow our focus on the lending sector and propose our blockchain-based solution.

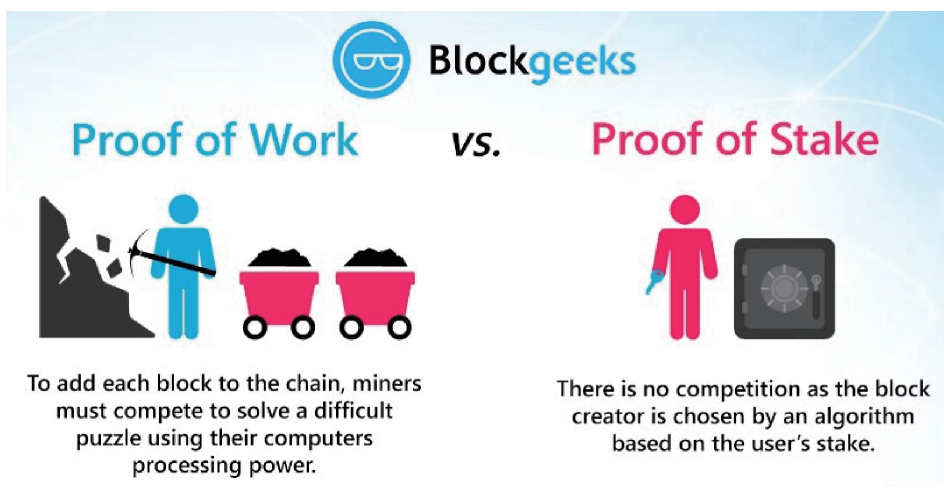

Figure 5 Proof of work vs. Proof of stake, Source: Blockgeeks.com, 2020

\subsection{Current Landscape and Proposed Solution}

Currently, there are multiple ways for people, mainly in the developed countries, to access short-term consumer credit. Firstly, credit card debt is by far the most widespread. It consists

\footnotetext{
${ }^{3}$ This figure shows how many blockchains use different transaction confirming mechanisms. It does not show the market share of each blockchain. PoW remains by far the largest.
} 
of unsecured, revolving loans which consumers can accumulate by opening credit card accounts with various institutions that offer different terms and credit limits. While very popular, credit card debt carries some of the highest interest rates in the industry, which it thus has in common with micro-loans in the developing countries (see Section 2). According to the Federal Reserve, the average credit card interest rate in the United States was around $16.5 \%$ in the first quarter of $2020^{[35]}$. A second short-term financing option are payday loans. Payday loans are shortterm loans which can range anywhere from $\$ 50$ to $\$ 1,000$ but come with very steep fees Around $\$ 15$ per $\$ 100$ borrowed and interest rates exceeding $100 \%$. These loans are extremely short-term and determined by local regulation and the applicant's pay check. They must be paid back on the borrower's next payday, unless they are extended, at which point additional charges apply and interest can skyrocket making payday loans a business often compared to loan sharking.

We propose a blockchain-based micro-lending platform which allows clients of partnered retail banks to dedicate a portion of their account balance to funding short-term, unsecured loans which carry much higher interest rates than simple savings accounts allowing higher profits for both bank and investors. On the other side, borrowers in need of short-term financing can sign-up for the platform and request small loans between $\$ 50 \sim \$ 2,000$ at interest rates between $5 \% \sim 10 \%$, which are significantly lower than interest rates on credit cards and payday loans. As the borrower repays his/her loans, his/her upper limit on loan volume increases. Transactions are fully automated by the use of smart contracts and recorded on a blockchain, which also allows for credit scoring in domains outside the platform - Punctually repaying clients will benefit from an improved credit history.

\section{Design}

\subsection{Business Concept}

In 2020, most retail banking transactions, such as acquiring a loan, still require intensive manual processing and documentation. They involve costly intermediaries and are timeconsuming as the transactions need to be validated by various bank parties at different points in time. Our platform aims to accomplish the task of connecting clients in need of small loans with clients of partnered retail banks with surplus wealth in a fast and easy way by employing smart contracts. Our aim is to facilitate small scale lending at high frequencies and shortterm duration ranging from a few days to weeks. Once a borrower requests a loan, he/she is automatically matched with a lender at a partnered bank that opted into a short-term loan program and the loan is executed expeditiously without the need for additional transaction fees and administrative effort.

\subsection{Mission}

Our mission is to enable an easier and more efficient way to connect small borrowers and lenders on a short-term basis. Banks usually prefer large loans to small ones since the latter generate fewer profits (if any at all, see Section 2) than the former simply due to the fixed costs associated with a loan application ${ }^{[36]}$. The unsecured, short-term loans they offer come with high interest rates. Clients in need of small, short-term loans would be able to get them at a 
reasonable cost and existing bank clients, which would like a low-effort way of earning interest without tying up their money for longer periods of time, would be able to do just that.

\subsection{Market Description}

The customer segment of interest are borrowers in need of short-term, small-sum loans and people looking to invest their excess wealth. Excess wealth are any funds deemed rife for investment in the short-term which also frees up significant amounts of money that people have previously been anxious to invest long term.

The initial market of focus is the United States where, in Q1 of 2020, revolving consumer debt reached $\$ 1.06$ trillion. More than 189 million Americans own credit cards, with an average of 4 per credit card holder. On average, each household with a credit card carries around $\$ 8,400$ in credit card debt ${ }^{[37]}$. According to a survey by the Federal Reserve, 4 in 10 American adults cannot afford to finance a hypothetical unexpected financial expense of $\$ 400$, using cash, savings, or a credit card paid off at the next statement ${ }^{[38]}$. The USA has two characteristics that make our solution well-suited to it (in the short run $)^{4}$ in terms of an entry market: A large network of retail banks and a significant proportion of the population that relies on short-term credit for their unexpected expenses. Moreover, the personal savings rate, calculated as the ratio of personal savings to disposable personal income, has seen a steady positive trend in the past 5 years, moving between $6 \%$ and $13 \%$, recently though skyrocketing to 20 to $32 \%$ in the wake of economic uncertainty due to the COVID-19 pandemic ${ }^{[39]}$. In the same time span or even over the last ten years, the interest rate broke $2 \%$ only once, with an average of about $1 \%[40]$. We believe our solution can improve upon the current options, such as credit card debt, borrowing from friends and family, and payday loans. Considering the low interest rate environment, our solution helps banks and lenders achieve higher returns on loan investments.

Our lending platform would enable this kind of quick, and especially, short-term lending not only in times of crisis but also on a daily basis. Thinking long-term, our service would see the highest benefits in countries where small, short-term loans were most necessary and which have an established retail banking sector.

\subsection{Value Proposition}

Our value proposition is multi-pronged and changes for different actors on our platform. To the borrowers, we enable fast and simple access to short-term financing with rates lower than those of existing forms of consumer debt. Due to the transactions being stored on the blockchain, upon the borrower's request his/her records could be sent to financial institutions and authorities as an influencing factor for their credit score. Borrowers would be limited to the number of loans they can take both by a fixed number and the amount they can borrow based on their credit history on the platform and outside it. For example, a borrower that can borrow a maximum of USD 1,500 can split this amount into a maximum of five loans.

To lenders, we enable a low-effort way of investing their excess wealth directly from their bank account, without it being tied up for long periods of time. The returns are significantly higher than on regular savings accounts.

\footnotetext{
${ }^{4}$ In the long run, an expansion to developing countries is indicated and required given the strong need for micro-loans there.
} 
For partnered banks, the main value proposition is the commission they take on additional loans as well as the reduction in credit risk (comparing many small loans to one big one with equal volume). A key aspect of loans is the credit default risk banks carry. In our solution, credits will be small and hence diversified, thus lowering the risk proportional to the volume, allowing banks to lend more money whilst still conforming to the Basel III standard of risk weighted assets. This risk is also significantly less correlated with macro-economic trends, for example a recession, reducing the institutional risk accordingly. These short-term loans could be dynamically adjusted to address credit risk and macroeconomic changes such as a recession. They would further, be an excellent way to distribute money to people in order to offset some of the financial pressure on families by COVID-19 whilst still conforming to risk regulations.

\subsection{Customer Relationships}

Trust, reliability, and transparency, which are in line with key blockchain features, are the main three pillars of our approach to customer relationships. The main contact channel for customers is an online platform, where borrowers sign up for our services. This would be integrated into the bank's online presence. Once a borrower is registered, he/she can immediately request a small loan. Lenders would sign up for our services through their local bank (due to regulatory requirements) but would receive support with regards to our services directly from our platform.

\subsection{Revenue Streams}

We have multiple revenue streams available to us. One option is that borrowers and lenders would pay the bank fixed percentage of the loan value as a transaction fee. We would then commission a secondary fee of the bank fee. We could also sell our solution as a finished product and leave the implementation to the banks. The problem with this approach is that patenting such a solution will be difficult. We believe to be in a strong negotiating position on the commission fees once we secure some patent, either on the blockchain solution side or the lending-transaction side. Ultimately, especially to diversify revenue streams, we suggest a very low commission transaction as well as a one-time fee per retail bank. We assume that to finance the technical implementation a strong relationship to a bank will be key. As a result, it is likely that the bank will acquire equity in our venture in the first place. The degree to which equity in the solution is controlled by the bank will largely determine the margins on transactions and revenues for the future.

\section{Evaluation: SWOT Analysis}

To test our idea and evaluate it from a more objective standpoint, we performed a SWOT analysis.

\subsection{Strengths}

Firstly, by using blockchain technology and smart contracts, we significantly improve the speed and reliability of transactions, as well as reduce information asymmetries and costs by eliminating the need for intermediaries and processes that usually take place before a person is granted a loan. For example, in contrast to often paper-based processes where account 
representatives fill in forms together with the customer applying for a loan, our proposal makes it lean and redesigns it from scratch: No more paper or front (for consulting) and back (for execution) office are required. Secondly, to the borrowers we enable simple access to shortterm financing. Thirdly, to lenders we offer an attractive, low-effort way of investing their surplus wealth at higher returns than simple savings accounts. Fourthly, partner banks receive a commission for each loan granted and get the opportunity to lend more money while still conforming to the Basel III standard. Lastly, the immutability of blockchain ensures transaction security.

\subsection{Weaknesses}

Under weaknesses, we identified our reliance on the acceptance of retail banks as the main supply issue, since our business model would have to be adapted should we not find enough partnered banks. For example, in case that bad scenario materializes, then we might need to move from the $\mathrm{B} 2 \mathrm{~B}$ to the $\mathrm{B} 2 \mathrm{C}$ realm which would come with high marketing expenses and customer acquisition costs. On the demand side, a lack of credit constrained consumers would be a weakness. We offer our solution with the intent of replacing other ways of short-term financing. Borrowers, however, could simply see our solution as an additional source of credit, thus indebting themselves more. Thirdly, our solution relies on a robust blockchain that utilizes the proof of stake mechanism. As of now, these blockchains are not yet robust enough.

\subsection{Opportunities}

First and foremost, expansion to markets other than the US is the main opportunity. For example, adapting our solution to make it applicable also in countries with less-established banking systems would allow us to enter massive underbanked markets where micro-lending is particularly needed, but often not working well (see Section 2). Secondly, developing the system to reach high loan volumes would give us a first-mover advantage and a possibility of automating bigger loan markets. We believe our solution is infinitely scalable and can replace the traditional lending activities entirely if we also adapt credit risk assessments for larger per-person volumes accordingly.

\subsection{Threats}

We identified two main threats. Firstly, our solution can be cloned by the banks themselves and integrated into their services. It is therefore necessary for us to protect our IP, for instance, by developing patentable blockchain solutions. Secondly, since we are dealing with very sensitive financial information, privacy concerns regarding user data can cause issues to arise quickly. Due to this reason, and because we rely heavily on the acceptance of banks, we assume that our service and idea will need to be integrated into the bank as well. This will limit our ability to scale to other retail banks accordingly.

\section{Conclusion}

Blockchain technology is among the most trending technologies ${ }^{[41]}$ and its features are argued to disrupt various businesses processes, industries and intermediary services ${ }^{[42]}$. Despite the great expectations though, there is currently a paucity of knowledge regarding where and 
how, i.e., regarding which (combinations of) features are relevant for particular industries, business processes and how they need to be designed ${ }^{[1]}$. These types of questions need to be tackled in order to influentially deploy the technology to business cases.

To sketch a blockchain use case in more detail, we looked at the current situation and trends in the retail banking and lending sector, with and without respect to blockchain technology. We identified energy consumption as the main culprit behind the limited spread of blockchain for lending solutions and concluded that a proof of stake blockchain incorporating smart contracts is currently the best available solution. Through this, we can automate and vehemently reduce lending fixed costs allowing more retail clients to participate in the market. As a consequence, clients in need are able to receive short-term low volume loans and other clients are able to profit from superior returns. Finally, we identified a potential entry market, the US. We developed a proposed solution to address it as well as antecedents for a business plan, which is currently tested with experts from the business practice and can thus serve as a starting point for what would arguably be a lucrative business filling a consumer need.

Except for its practical relevance detailed in the previous sections (accounting for a differentiation between different stakeholders), our study's contribution to academic research is threefold: First, we extend the knowledge on blockchain-based financial products and provide a sound business concept for micro-lending in retail banking, building on smart contracts, which drastically diminishes transaction and administration costs, hitherto inherent to microfinance. Second, we adopt the concept of trust-free economic systems ${ }^{[43]}$ to the use case of small shortterm loans in retail banks and introduce a novel way to replace trust-based and centralized bureaucratic registries with a trust-free, cost-efficient transaction system. Third, we alleviate adverse selection effects and dismantle information asymmetries between borrowers and lenders by sharing and assessing a transparent, reliable, and complete record of credit and repayment history. Nonetheless, we realize that much more work would be needed, especially on the technical and regulatory sides, to turn our idea into veritable impact.

\section{References}

[1] Risius M, Spohrer K. A blockchain research framework. What we (don't) know, where we go from here, and how we will get there. Business \& Information Systems Engineering, 2017, 59(6): 385-409.

[2] Beck R. Beyond bitcoin: The rise of blockchain world. Computer, 2018, 51(2): 54-58.

[3] Fridgen G, Lockl J, Radszuwill S, et al. A solution in search of a problem: A method for the development of blockchain use cases. 24th Americas Conference on Information Systems, 2018: 1-10.

[4] Labazova O, Dehling T, Sunyaev A. From hype to reality: A taxonomy of blockchain applications. Proceedings of the 52nd Hawaii International Conference on System Sciences, 2019.

[5] Glaser F. Pervasive decentralisation of digital infrastructures: A framework for blockchain enabled system and use case analysis. 50th Hawaii international conference on system sciences (HICSS 2017), Waikoloa, 2017.

[6] Lee D K C, Lim C. Blockchain use cases for inclusive FinTech: Scalability, privacy, and trust distribution. 2019, https://ssrn.com/abstract $=3629135$.

[7] Johnson C. Payday loans: Shrewd business or predatory lending. Minnesota Law Review, 2002,87 : 1.

[8] Skiba P M, Tobacman J. Payday loans, uncertainty and discounting: Explaining patterns of borrowing, repayment, and default. Van-derbilt Law and Economics Research Paper, 2008.

[9] Skiba P M, Tobacman J. Do payday loans cause bankruptcy? The Journal of Law and Economics, 2019, $62(3): 485-519$. 
[10] Banerjee A. Micro-credit under the microscope: What have we learned in the past two decades, and what do we need to know? Annual Review of Economics, 2013, 5(1): 487-519.

[11] Duggan C S. Doing bad by doing good? Theft and abuse by lenders in the microfinance markets of Uganda. Studies in Comparative International Development, 2016, 51(2): 189-208.

[12] Chatterjee S, Singla V, Lam M. How blockchain can reshape trade finance. (2020-05-06) [2020-05-21]. https://www2.deloitte.com/content/dam/Deloitte/global/Documents/grid/trade-finance-placemat.pdf.

[13] Cuellar Benavides J P. Blockchain: Decentralization as the future of microfinance and financial inclusion. HEC Paris, 2019.

[14] Kringlen M. The relationship between default on loans and operating costs in microfinance institutions. University of Agder, 2016.

[15] Wild J, Arnold M, Stafford P. Technology: Banks seek the key to blockchain. Financial Times, 2015, 1: 2015.

[16] Garmaise M J, Natividad G. Information, the cost of credit, and operational efficiency: An empirical study of microfinance. The Review of Financial Studies, 2010, 23(6): 2560-2590.

[17] Higginson M, Hilal A, Yugac E. Blockchain and retail banking: Making the connection. (2019) [2020-05-12]. https://www.mckinsey.com/industries/financial-services/our-insights/blockchain-and-retailbanking-making-the-connection.

[18] Notheisen B, Cholewa J B, Shanmugam A P. Trading real-world assets on blockchain. Business \& Information Systems Engineering, 2017, 59: 425-440.

[19] Chikalipah S. Credit risk in microfinance industry: Evidence from sub-Saharan Africa. Review of Development Finance, 2018, 8: 38-48.

[20] Winter R. Interview mit Alan R. Hevner zum Thema, Design Science. Wirtsch. Inform., 2009, 51: 148-151.

[21] Hyvärinen H, Risius M, Friis G. A blockchain-based approach towards overcoming financial fraud in public sector services. Business \& Information Systems Engineering, 2017, 59: 441-456.

[22] Peffers K, Tuunanen T, Rothenberger M A, et al. A design science research methodology for information systems research. Journal of Management Information Systems, 2007, 24(3): 45-77.

[23] Angerer M, Hoffmann C H, Neitzert F, et al. Objective and subjective risks of investing into cryptocurrencies. Finance Research Letters, 2020. https://doi.org/10.1016/j.frl.2020.101737.

[24] IDC. Worldwide Semiannual Blockchain Spending Guide. 2019. https://www.idc.com/getdoc.jsp?containerId =IDC_P37345.

[25] Consensys. Blockchain in Financial Services. [2020-05-05]. https://consensys.net/blockchain-use-cases/finance/.

[26] Tschorsch F, Scheuermann B. Bitcoin and beyond: A technical survey on decentralized digital currencies. IEEE Commun. Surv. Tutor., 2016, 18(3): 2084-2123.

[27] Visa. Visa Fact Sheet. (2019) [2020-05-12]. https://usa.visa.com/dam/VCOM/global/about-visa/documents/visa-fact-sheet-april-2019.pdf.

[28] Sedlmeir J, Buhl H U, Fridgen G, et al. The energy consumption of blockchain technology: Beyond myth. Business \& Information Systems Engineering. 2020. https://doi.org/10.1007/s12599-020-00656-x.

[29] Beck R, Müller-Bloch C, King J L. Governance in the blockchain economy: A framework and research agenda. Journal of the Association for Information Systems, 2018, 19(10): 1020-1034.

[30] Bitcoin Electronic Waste Monitor. [2020-05-05]. https://digiconomist.net/bitcoin-electronic-waste-monitor/.

[31] Powercompare. (2018) [2020-05-10]. https://powercompare.co.uk/bitcoin/on 10.05.2020.

[32] Xue T, Yuan Y, Ahmed Z, et al. Proof of contribution: A modification of proof of work to increase mining efficiency. Proceedings of the 2018 IEEE 42nd Annual Computer Software and Applications Conference (COMPSAC), 2018, 1: 636-644.

[33] Sutherland B R. Blockchain's first consensus implementation is unsustainable. Joule, 2019, 3(4): 917-919.

[34] De Vries A. Renewable energy will not solve bitcoin's sustainability problem. Joule, 2019, 3(4): 893-898.

[35] Federal Reserve. Consumer Credit report. (2020-05-07) [2020-05-19]. https://www.federalreserve.gov/releases/g19/current/.

[36] Eichengreen B, Mody A. Lending booms, reserves, and the sustainability of short-term debt: Inferences from the pricing of syndicated bank loans. The World Bank, 1999.

[37] Fay B. Key figures behind America's credit card debt. (2019) [2020-05-19]. https://www.debt.org/ 
faqs/americans-in-debt/.

[38] Federal Reserve. Report on the Economic Well-Being of U.S. Households in 2018-May 2019. (2019) [2020-05-19]. https://www.federalreserve.gov/publications/2019-economic-well-being-of-us-households-in2018-dealing-with-unexpected-expenses.htm.

[39] Statista. Personal saving rate in the United States from June 2015 to May 2020. [2020-07-07]. https://www.statista.com/statistics/246268/personal-savings-rate-in-the-united-states-by-month/.

[40] Statista. Monthly Federal funds effective rate in the United States from January 2000 to June 2020. [202007-07]. https://www.statista.com/statistics/187616/effective-rateof-us-federal-funds-monthly/.

[41] Gartner. Gartner's 2018 hype cycle for emerging technologies identifies five key trends that organizations must track to gain competitive advantage. (2018) [2020-07-03]. https://www.gartner.com/ smarterwithgartner/5-trends-emerge-in-gartner-hype-cycle-for-emerging-technologies-2018.

[42] Tapscott D, Tapscott A. The impact of the blockchain goes beyond financial services. Harvard business review. 2016. https://hbr. org/2016/05/the-impact-of-the-blockchain-goes-beyond-financial-services.

[43] Beck R, Stenum Czepluch J, Lollike N, et al. Blockchain - The gateway to trustfree cryptographic transactions. 24th European Conference on Information Systems (ECIS), 2016. 